\title{
tropas conduzidas pela barreira de itapetininga e o comportamento do mercado de muares, 1854-69*
}

\section{Carlos Eduardo Suprinyak - Unesp}

Mestre em Economia, Programa de Pós-Graduação em Economia, área de concentração História Econômica. Faculdade de Ciências e Letras, FLC, Universidade Estadual Paulista Júlio Mesquita Filho, UNESP, Campus de Araraquara. Email: suprinyak@ cedeplar.ufmg.br

\begin{abstract}
RESUMO
O presente artigo oferece novas perspectivas em relação ao comércio de tropas de muares no Brasil imperial, utilizando a herança documental da barreira de Itapetininga — parte do sistema de arrecadação dos direitos sobre animais da Província de São Paulo. Após discutir as estimativas elaboradas até hoje e as características da documentação da barreira, apresentamos a série estatística elaborada com base nesta, que cobre o período 1854-69. Discute-se, a partir dela, a evolução do negócio, suas oscilações e tendências, além de compará-la à série elaborada por Herbert Klein, com base na documentação do registro de Sorocaba. Além disto, apresentamos também um estudo sobre os padrões de concentração do comércio e sua evolução ao longo do período, com base na análise da distribuição das tropas conduzidas
\end{abstract}

\section{I - Breve retrospecto histórico}

Seria ocioso insistir sobre a fundamental importância das mulas sulistas como meio de transporte de carga para o complexo produtor do centro-sul do Brasil (Minas Gerais, São Paulo e Rio de Janeiro), durante o século XIX. Sobre este ponto, parece haver um consenso longamente estabelecido em nossa historiografia, corroborado por nomes como Caio Prado Jr., Celso Furtado e Alfredo Ellis Jr., tendo-se dispensado bastante ênfase ao papel desempenhado pelo sistema de abastecimento destes animais, seja na viabilização das atividades produtivas do centrosul, seja no desenvolvimento das regiões meridionais do Brasil - em especial Rio Grande do Sul e Paraná. Obtendo seu impulso inicial

Submetido: setembro, 2005; aceito, dezembro, 2005. 
durante o século XVIII, em função das necessidades da atividade mineradora, este sistema de abastecimento sobreviveria ao declínio dela, inserindo-se de forma orgânica no processo de diversificação produtiva e desenvolvimento das culturas canavieira e cafeeira ao longo do período imperial.

Embora a expansão da rede ferroviária brasileira, ocorrida a partir de meados do século XIX, tenha finalmente cerceado o desenvolvimento do negócio dos muares, impondo-lhe severo declínio com a proximidade do fim do período imperial, durante o seu apogeu atingiu proporções marcantes, a indicar quão notável teria sido sua relevância econômica'. Desenvolvendo-se em linha com o crescimento das produções de cana-de-açúcar e, principalmente, café, o comércio de bestas de carga oriundas do extremo sul atingiria o ápice nas décadas de 1850 e 1860, sendo deslocado a partir de 1870 para uma posição secundária, associada ao transporte de cargas a pequenas distâncias. Entretanto, enquanto funcionou propriamente, pode-se seguramente atribuir-lhe a responsabilidade pela geração de grandes volumes de renda e riqueza, apropriadas por significativas parcelas das populações gaúcha, paranaense e paulista.

A preferência pelas mulas em detrimento de outros animais, no escoamento das produções da região central em direção aos portos de exportação, explica-se, em grande medida, pela maior adaptabilidade deste animal às características acidentadas do relevo da região ${ }^{2}$. Tal aspecto, ao impedir a construção de estradas satisfatoriamente trafegáveis, inviabilizava a utilização dos carros de bois como meio de transporte de cargas. As mulas, embora mais lentas, mostravam-se mais resistentes do que as raças de cavalos existentes no Brasil, sendo capazes de transpor os obstáculos geográficos dos percursos, mesmo quando carregadas com gêneros.

Se a demanda pelos muares assim se explica, o surgimento do extremo sul do Brasil como principal pólo ofertante destes animais também pode ser compreendido em termos geográficos. A região do Rio da Prata é composta por um conjunto de planícies altamente favoráveis à

Para que se tenha idéia da relevância fiscal dos direitos sobre os animais, considerese o valor da receita provincial de São Paulo no ano financeiro 1860-61 como sendo igual a 1.299:110\$116, conforme apresentado por COSTA (1984, p. 194). Neste mesmo ano financeiro, o valor total dos direitos sobre os animais passados por Itapetininga foi $156: 833 \$ 820$ - ou seja, mais de $12 \%$ do total da receita provincial.

Ver, a este respeito, PRADO JR. (2001, p. 208) e CALÓGERAS (1945, p. 1672). 
atividade pecuária. No caso especial das mulas, ELLIS JR. (1979, p. 85) afirma ser esta a região mais propícia de toda a América do Sul para sua criação. Acrescente-se a isto o fato de que, desde o século XVII, a criação de mulas já era desenvolvida na região, visando o abastecimento da demanda por animais de carga nas minas de prata de Potosí. Com o declínio desta atividade mineradora, verificou-se o deslocamento de um complexo produtor em direção a novos centros consumidores - no caso, as áreas brasileiras empenhadas na mineração do ouro - com as evidentes vantagens decorrentes deste pioneirismo.

A existência, a meio caminho entre os pólos ofertante e demandante, de uma extensa área geográfica composta majoritariamente por planícies ideais para a pastagem de rebanhos - os Campos Gerais, hoje pertencentes ao estado do Paraná - também contribuiu para estabelecer em bases bastante sólidas o sistema de abastecimento de muares vindos do sul com destino a São Paulo e demais regiões consumidoras. Após a exaustiva e desgastante viagem desde a região do Prata, atravessando os temidos "sertões lajeanos", as tropas podiam ser recuperadas e engordadas nas inúmeras estações de invernagem estabelecidas nos Campos Gerais, antes de serem remetidas para comercialização em feiras realizadas em território paulista - a principal delas localizada em Sorocaba. Tal arranjo estrutural acabou por ensejar o envolvimento dos habitantes dos Campos Gerais na aquisição e na condução das tropas desde o Rio Grande do Sul, atividade pela qual se tornaram os principais responsáveis (WESTPHALEN, 1995, p. 14).

Assim, formou-se e consolidou-se o sistema de comercialização dos muares do sul, cuja principal rota de abastecimento foi o chamado "caminho do Viamão", a ligar a cidade homônima - localizada em território gaúcho - à capital paulista, atravessando, em seu trajeto, as densas florestas catarinenses e as planícies dos Campos Gerais, e passando por cidades como Vacaria, Lajes, Rio Negro, Ponta Grossa, Itapetininga e Sorocaba ${ }^{3}$. A primeira passagem de tropas pelo caminho deu-se em 1731, sob a responsabilidade de Cristóvão Pereira de Abreu ${ }^{4}$, mas foi somente a partir do segundo quartel do século XIX - após a abertura

Uma descrição sumária do caminho pode ser encontrada em PELADO JR. (2001, p. 252), enquanto WESTPHALEN (1995, pp. 12-14) oferece uma descrição mais detalhada do mesmo.

Ver MOREIRA (1975, p. 713) e HAMEISTER (2002, pp. 109-133). 
da Estrada da Mata (ligando Lajes a Rio Negro), por obra de João da Silva Machado, futuro Barão de Antoninas - que o volume de tropas por ali conduzido passou a crescer significativamente.

Em consequiência do sensível aumento na quantidade de animais conduzidos pelo caminho, cresceu também a preocupação com a fiscalização e a arrecadação de impostos sobre o florescente negócio. Inicialmente pertencentes à Fazenda Real - e por ela arrematados a terceiros $^{6}$ - os direitos cobrados sobre os animais vindos do sul foram incorporados às receitas da Província de São Paulo a partir de 1826 (LAVALLE, 1974, p. 20). Devido a seu alto valor em comparação com outros impostos', a condução a bom termo de sua cobrança logo se tornou uma preocupação do governo provincial. Criou-se, desta forma, uma rede apropriada para tanto. Instituído com esta finalidade, quando da abertura do caminho do Viamão ${ }^{8}$, o registro de Curitiba localizava-se em posto não favorável ao bom desempenho de suas funções, pois permitia que as tropas vindas do sul evitassem o pagamento dos direitos, desviando o registro a leste, através de rotas clandestinas que ligavam diretamente aos Campos Gerais (LAVALLE, 1974, pp. 21-22). Para contornar tal problema, fundou-se o registro do Rio Negro, localizado na saída da Estrada da Mata (único caminho para travessia dos

Ver, a respeito, MOREIRA (1975, pp. 717-733) e ALMEIDA (1947).

Veja-se a respeito PETRONE (1976) e LAVALLE (1974, p. 21).

Valores dos direitos devidos sobre os animais soltos (i.e., sem carga): muares: $2 \$ 500$; cavalos: $2 \$ 000$; éguas: $\$ 960$; reses: $\$ 480$. Cf. disposição de 17 de dezembro de 1768 , no contrato do registro de Curitiba, apud WESTPHALEN (1995, p. 14). Estes valores permaneceram constantes durante todo o período imperial. A título de comparação, o valor do "novo imposto", cobrado sobre os muares em Sorocaba, era de \$320 em 1836, cf. MULLER (1978, p. 209).

Há certa controvérsia com relação à data de criação do registro de Curitiba. WESTPHALEN (1995, p. 14) afirma que o registro foi instituído em 1748, provavelmente com base na data de publicação do regimento desta unidade fiscal. Entretanto, parece mais provável que este regimento tenha apenas oferecido um marco regulatório mais preciso para o funcionamento de um registro, já em atividade há muitos anos. PETRONE (1976, p. 162) situa a criação do registro em 1732, logo após a abertura do caminho do Viamão. Por outro lado, MOREIRA (1975, p. 781) recorre a um mapa dos Campos Gerais, elaborado em 1728, onde se encontra indicado o local do registro de Curitiba, para argumentar que este já existia quando da abertura do caminho das tropas, tendo sido criado para fiscalizar o intermitente fluxo de animais conduzidos pelas rotas litorâneas. 
sertões da região de Santa Catarina com destino ao sul), às margens do rio homônimo, passando este a ser o responsável pela emissão das guias para cobrança dos direitos a partir de 12 de agosto de $1829^{10}$.

As guias para recolhimento dos direitos sobre as tropas foram emitidas pelo registro do Rio Negro até meados da década de 1850, quando, na iminência da emancipação da Província do Paraná, o governo provincial paulista determinou nova transferência na localização do registro através da lei provincial $\mathrm{n}^{\circ} 10$, de 7 de maio de 1851. As guias passaram a ser emitidas na barreira de Itapetininga, Província de São Paulo, a partir de 15 de janeiro de 1854 (LAVALLE, 1974,p. 27), logrando o governo paulista evitar a perda da arrecadação dos valiosos direitos. A barreira de Itapetininga seria a responsável pela emissão das guias até princípios da década de 1870, quando o comércio dos muares já começava a se desorganizar, em função da chegada das ferrovias. A contribuição para o estudo da matéria a ser oferecida pelo presente artigo está fundamentada nos registros de passagem de tropas por esta barreira.

\section{II - Séries disponíveis}

Ao longo das últimas décadas, foram empreendidas algumas tentativas de mensuração da magnitude do comércio dos muares vindos do sul com destino a São Paulo. Superando estimativas pioneiras - e precárias - aventadas por Aluísio de Almeida ${ }^{11}$, pesquisas mais recentes, atra-

\footnotetext{
"O sistema de arrecadação dos direitos sobre os animais vindos do sul possuía características bastante peculiares. Devido em grande medida à escassez do meio circulante, o imposto não era recolhido no local do registro. Ao passar por este, o condutor apenas recebia uma guia que registrava informações sobre sua tropa e que devia ser paga em Sorocaba, dentro de prazo determinado.

${ }^{10}$ Segundo LAVALLE (1974, p. 26), há controvérsia com relação a este ponto. MOREIRA (1975, p. 857), por exemplo, afirma que a transferência do local do registro só foi efetivada com a promulgação da lei provincial $n^{o}$ 11, de 24 de março de 1835.

"Os números apresentados em ALMEIDA (1945, pp. 168-169) serviram como base para a elaboração do clássico artigo de ELLIS JR. (1950), embora sua verossimilhança seja bastante questionável. O próprio Aluísio de Almeida, em trabalho publicado posteriormente, propõe outros números bastante diversos. Não se sabe ao certo qual foi a base documental utilizada por Almeida na elaboração das estimativas referenciadas por Ellis Jr. De qualquer forma, elas estão em clara divergência com todas as evidências documentais desde então encontradas.
} 
vés de esforços de seriação de fontes documentais do período, conseguiram oferecer um quadro mais preciso acerca das dimensões e da evolução deste negócio.

O trabalho mais antigo a oferecer informações quantitativas confiáveis quanto ao volume de animais conduzidos pelo caminho do Viamão é o de LAVALLE (1974), cuja divulgação até o momento foi, surpreendentemente, bastante restrita. Sua base documental é composta pelos livros do registro do Rio Negro, onde as guias para pagamento dos direitos sobre os animais vindos do sul foram emitidas de 1829 a 1854. As informações, de natureza bastante homogênea, encontram-se disponíveis para a quase totalidade do período, à exceção do ano financeiro de 1831/2 e de alguns anos ao fim da década de 1840 e princípio da década de 1850. O volume de animais conduzidos a Sorocaba, de acordo com sua estimativa, oscilou entre 10 e 17 mil bestas nos primeiros anos da década de 1830, chegando a 20 mil em meados da década e ultrapassando 40 mil animais já na segunda metade desta. Manter-se-ia entre 25 e 40 mil animais até o final do período, apresentando grande oscilação ano a ano (LAVALLE, 1974, pp. 125-149).

É importante ressaltar que, ao elaborar sua série estatística, Lavalle compilou apenas as informações relativas às "tropas guiadas" - isto é, as que se dirigiam à feira de Sorocaba. Isto significa que os números por ela estimados não contabilizam os animais vindos do sul, que foram comercializados na região dos Campos Gerais, ao sul de Sorocaba. Segundo ela, o volume deste comércio "a formiga", como era chamado, não chegaria a $5 \%$ do total das tropas transacionadas em um ano financeiro dado (LAVALLE, 1974, p. 10).

Ainda na década de 70, PETRONE (1976) também empreendeu uma tentativa de mensuração do volume de animais negociados na região de Sorocaba, baseando-se para tanto na documentação pessoal de Antônio da Silva Prado, o Barão de Iguape. Conseguiu, desta forma, estimar com bastante precisão o número de muares negociados na feira de Sorocaba, em princípios da década de 1820. Seu levantamento baseia-se nos livros de cobrança do Novo Imposto e do Imposto de Guarapuava, ambos cobrados sobre a passagem de tropas de animais soltos, e que foram arrematados por Prado durante o triênio 1820-22 - período bastante reduzido, porém de valioso auxílio ao fornecer indicações mais precisas sobre o estado dos negócios no início do período imperial. 
Suas estimativas para o período oscilam entre 14 e 21 mil animais por ano, aproximadamente.

Em trabalho mais recente, KLEIN (1989) construiu uma série de volumes negociados com base nos livros do registro de Sorocaba. Sua série, mais abrangente, cobre o período 1825-1880 e suas estimativas tendem a confirmar a linha de evolução tradicionalmente estabelecida, com ascensão contínua no volume negociado até a década de 1860 e queda abrupta a partir da década de 1870 - a média anual caindo de 40 para 17 mil animais de um decênio para o outro (KLEIN, 1989, pp. 370372). O autor, entretanto, não compilou as informações disponíveis nestes livros ano a ano, valendo-se de alguns anos selecionados para estimar as proporções entre os diversos tipos de animais e sua mudança ao longo do tempo, compondo a série através da combinação destas proporções com os valores recolhidos em impostos (p. 354). Vale ainda lembrar que os registros utilizados por Klein são os do "Novo Imposto de Animais" - os mesmos utilizados por Petrone, de natureza diversa dos direitos sobre animais que compõem a base documental de Lavalle ${ }^{12}$.

\section{III - A série de Itapetininga}

\section{A - Herança documental}

O corpo documental legado pela barreira de Itapetininga - onde as guias para cobrança dos direitos sobre animais vindos do sul foram emitidas de 1854 até princípios da década de 1870 - é bastante extenso, completo e rico em informações ${ }^{13}$. Além de correspondências e escriturações contábeis, é composto por seis tipos básicos de documentos: livros da barreira de Itapetininga e suas agências, onde são registradas as passagens de animais carregados com gêneros, que pagam apenas a correspondente taxa de barreira; livros de direitos pagos à vista, que registram os direitos sobre animais não destinados à feira de Sorocaba, sobre os quais tal direito era recolhido na própria barreira; livros de termos de fiança das tropas guiadas, que reproduzem os documentos de fiança das

\footnotetext{
${ }^{12}$ Ver notas 7 e 9 .

${ }^{13}$ Estes documentos encontram-se no Arquivo Público do Estado de São Paulo, sob o título "Livros de Barreiras - Itapetininga".
} 
tropas conduzidas a Sorocaba; segundas vias das guias emitidas para pagamento dos direitos em Sorocaba; mapas dos direitos pagos à vista $\mathrm{e}$ das tropas guiadas, que representam de forma reduzida e sistemática a sua movimentação nestas duas modalidades de recolhimento dos direitos. Os diversos documentos estão disponíveis, com falhas ocasionais, para todo o período 1854-1869, à exceção dos mapas de direitos à vista, cujos exemplares mais antigos encontrados se referem ao ano de 1861.

Para os propósitos de mensuração do comércio de animais, os livros de barreira são dispensáveis, pois registram tão somente o movimento de animais carregados. Os demais documentos podem ser divididos em dois grupos, de acordo com a modalidade de recolhimento dos direitos a que se referem: tropas guiadas ou direitos pagos à vista. Os pertencentes ao primeiro grupo dizem respeito aos animais cujo destino é Sorocaba, onde serão recolhidos os direitos. Já os integrantes do segundo grupo se referem, muito provavelmente, às tropas a serem comercializadas na região dos Campos Gerais, ao sul de Sorocaba ${ }^{14}$.

No presente trabalho, optou-se por utilizar apenas as informações relativas às tropas guiadas, isto é, aos animais com destino a Sorocaba. Esta escolha está fundamentada, basicamente, em dois aspectos. Em primeiro lugar, os registros de direitos pagos à vista apontam para um padrão de comportamento sazonal bastante diverso do apresentado pelas tropas guiadas, com uma distribuição mais uniforme do fluxo ao longo do ano. Isto posto, e tendo-se em mente que estes animais estavam, na hipótese mais provável, relacionados a um comércio local de menores proporções, sua inclusão na série acabaria por distorcer os resultados, afastando-a de uma aferição mais pura do fluxo de animais vindos do sul com destino aos mercados de São Paulo e regiões mais ao norte. Em nossa opinião, os registros de direitos pagos à vista merecem ser analisados separadamente com a devida atenção - trabalho que demandará

A diferenciação entre o pagamento à vista e o efetuado com guias estava baseada no valor dos direitos - se o valor total fosse inferior a 50\$000, recolhia-se à vista (LAVALLE, 1974, p. 8). Entretanto, a própria autora afirma, mais adiante, que os direitos à vista estavam em sua maior parte relacionados a tropeiros da região dos Campos Gerais, sem ligação com a feira de Sorocaba (LAVALLE, 1974, p. 10). Além disto, a existência de um padrão de sazonalidade nas passagens bastante diverso entre as duas modalidades parece corroborar a idéia de que há uma diferença mais essencial entre suas naturezas. 
razoável esforço - antes de serem integrados às tropas guiadas, numa análise mais abrangente do mercado de muares.

Em segundo lugar, a exclusão dos direitos pagos à vista na construção da série permitirá uma confrontação mais direta entre esta e as demais estimativas disponíveis. Na construção de sua série, LAVALLE (1974, pp. 7-10) excluiu explicitamente os registros de direitos pagos à vista, atendo-se unicamente aos livros de tropas guiadas. Sua abordagem, partindo de um conjunto documental análogo, assemelha-se muito à nossa. Por outro lado, por trabalhar com a documentação do próprio registro de Sorocaba, KLEIN (1989) também não está apto a captar este fluxo marginal de animais. Uma série baseada exclusivamente nos registros de tropas guiadas pela barreira de Itapetininga, além de funcionar como uma extensão da elaborada por Lavalle para a primeira metade do século, também viabilizará um diálogo mais confiável com os resultados de Klein.

\section{$B$ - Apresentação da série}

A série aqui apresentada foi elaborada tendo como base principal os mapas de tropas guiadas pela barreira, disponíveis para o período 1854/55-1857/58 e 1861/62-1868/69. Com relação ao período 1858/ 59-1860/61, durante o qual falham os mapas, utilizaram-se os livros de termos de fiança para complementar, sem prejuízos, as informações. Tais livros também foram usados para cobrir falhas eventuais nos demais anos, onde elas se fizeram presentes, viabilizando a compilação completa da série, sem necessidade de recorrer a técnicas estatísticas de interpolação. Respeitou-se a periodização apresentada nos documentos originais, baseada em anos financeiros, que se iniciam em $1^{\circ}$ de julho e terminam em 30 de junho do ano seguinte.

Os dados da tabela 1 evidenciam a magnitude do negócio dos muares durante as décadas de 1850 e 1860, atingindo seu ápice no ano de 1856/ 57 , quando mais de $60 \mathrm{mil}$ bestas passaram pela barreira. Este ápice foi seguido por uma queda abrupta no ano seguinte, porém retornando posteriormente a altos patamares, até princípios da década de 60. A partir de 1862/63, uma crise de grandes proporções atinge o mercado, reduzindo o volume conduzido anualmente a menos da metade. A recuperação apenas viria no final da década, quando o mercado retoma os níveis 
do início do decênio. O volume de cavalos conduzidos pela barreira apresenta padrão ligeiramente diferente, declinando de forma mais suave, porém constante, desde seu pico, do final da década de 1850, até o fim do período. Tais tendências podem ser mais bem captadas através do gráfico 1, que exibe a evolução do volume de animais conduzidos. Em particular, a suavização da série dos muares, através de um processo de médias móveis de três anos, evidencia claramente as três etapas verificadas: apogeu, crise e recuperação.

Gráfico 1. Volume de animais conduzidos anualmente pela barreira de Itapetininga, $1854 / 55$ - $1868 / 69$

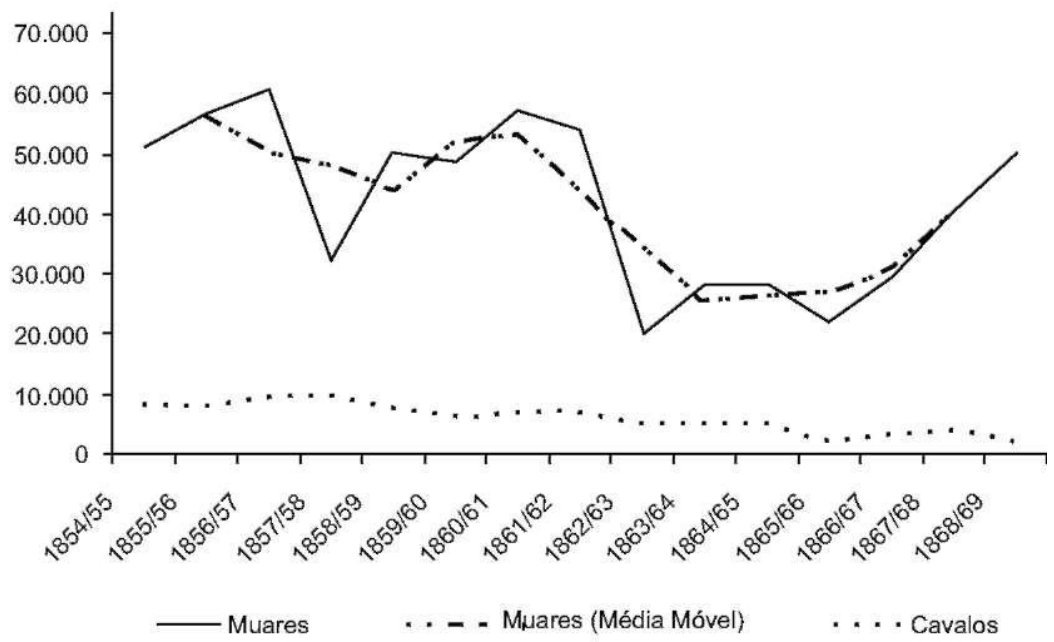

A sazonalidade na passagem das tropas pela barreira de Itapetininga apresenta um padrão bastante semelhante ao encontrado por KLEIN (1989, pp. 358-361). O período de maior movimentação no mercado de muares encontra-se, sem dúvida, nos meses de abril e maio ${ }^{15}$, com um

\footnotetext{
"Tal fenômeno se explica por uma conjunção de fatores favoráveis: em primeiro lugar, a época do ano mais propícia para a condução das tropas pelo caminho do Viamão era a estação chuvosa (iniciada em setembro, aproximadamente), dado que, neste período, a fertilidade dos pastos estava em seu ponto máximo, facilitando a alimentação e a engorda dos animais. Além disto, após o fim da estação chuvosa, iniciava-se o período de colheita do açúcar e do café, para cujo transporte se demandavam os muares. Em estreita correlação com estes dois fatores, a feira de Sorocaba era realizada precisamente neste período (segundo trimestre de cada ano).
} 
pico de menor relevância ocorrendo também nos meses de dezembro e janeiro. Quando analisada em relação ao conjunto de todos os rebanhos, a sazonalidade na passagem de animais se mostra um pouco mais suave, embora apresentando os mesmos traços gerais. A razão fica clara, quando se leva em conta o padrão apresentado pelas passagens de cavalos, cujo pico ocorre nos meses de dezembro e janeiro, aparecendo abril e maio como meses apenas medianos. Esta diferença nos padrões de sazonalidade pode apontar para a existência de estruturas de comercialização diversas entre os mercados de muares e cavalos.

Gráfico 2. Média de animais conduzidos pela barreira de Itapetininga, segundo meses do ano, $1854 / 55-1868 / 69$

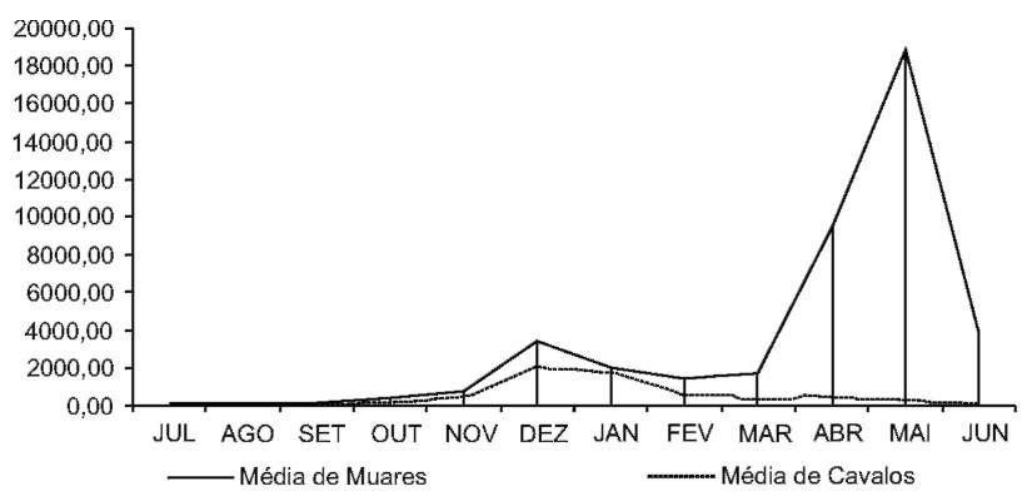

Confrontando a série aqui apresentada, baseada na documentação da barreira de Itapetininga, com as estimativas propostas por KLEIN (1989, pp. 370-372) para o mesmo período, verifica-se uma evolução semelhante, em linhas gerais, conforme pode ser observado no gráfico 3 . Entretanto, embora a tendência seja semelhante, as flutuações na série de Itapetininga são muito mais bruscas do que as presentes na série de Klein, baseada nos registros de Sorocaba. Assim, embora a série de Klein também aponte uma queda no ano 1857/58, ela é muito menos pronunciada do que a verificada em nossa série. Da mesma forma, a crise da década de 1860 é precipitada de forma muito mais marcante em nossa série do que na série de Sorocaba. A comparação entre a série de Itapetininga, ajustada com médias móveis de três anos, e a série de Sorocaba parece fornecer ainda mais evidências de que o fluxo de Sorocaba refle- 
te o de Itapetininga, porém de forma suavizada. A semelhança entre estas duas séries é notável, como se pode constatar através do gráfico 3.

Gráfico 3. Volume de muares conduzidos por Itapetinga e Sorocaba, 1854/55 - 1858/59

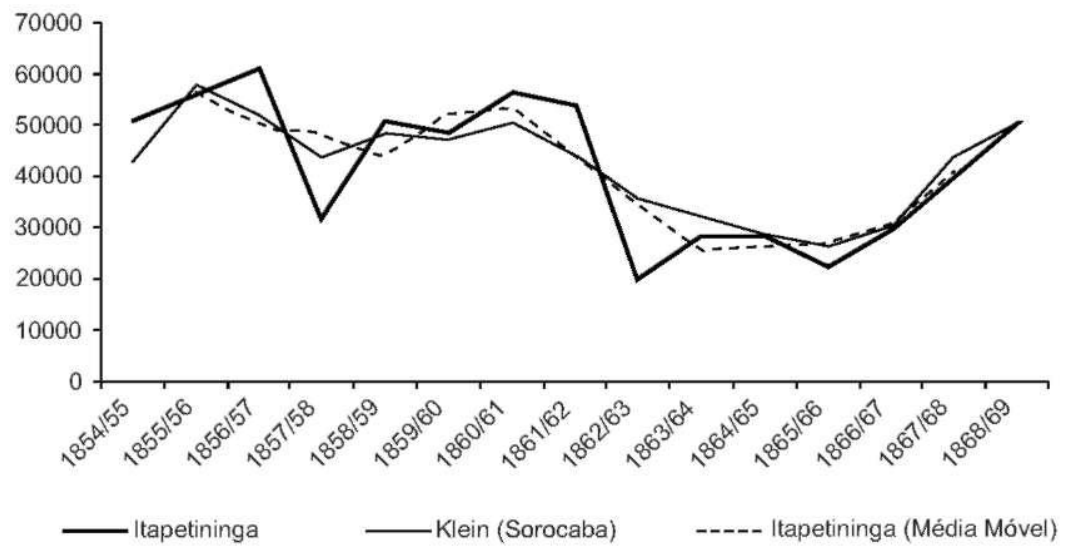

O que poderia explicar tal diferença nas flutuações entre as duas séries? Ao longo do século XIX, paralelamente ao crescimento do negócio dos muares, parece ter-se desenvolvido um sistema de comercialização bastante avançado em torno deste ${ }^{16}$. Ao menos no que tange aos negócios de grande porte, sua consumação envolvia diversas etapas, assim como exigia os esforços de vários indivíduos. Para que se tenha idéia da dimensão de uma operação de grande porte com tropas, suponhamos que o valor de venda médio de uma besta na feira de Sorocaba, em meados do século XIX, fosse de 50 mil-réis ${ }^{17}$. Desta forma, uma tropa de 700 bestas - bastante comum - poderia ser negociada pela fabulosa quantia de 35 contos de réis. Em operações de semelhante

${ }^{16}$ Já durante a década de 1820 PETRONE (1976) pôde desvendar uma complexa estrutura de comercialização de tropas - envolvendo inclusive separação entre as atividades de condução e comercialização dos animais - através de sua análise da documentação pessoal de Antônio da Silva Prado, o Barão de Iguape, comerciante que desempenhou importante papel nesta atividade em princípios do século XIX. WESTPHALEN (1995) também fornece indícios da magnitude das estruturas econômicas montadas em torno dos grandes negócios com tropas em meados do século. ${ }^{17}$ PETRONE (1976, pp. 29) estima que,já na década de 1830, o preço de uma besta em Sorocaba oscilava entre 40 e 60 mil-réis.

601 Carlos Eduardo Suprinyak 
vulto, é de se esperar que haja um cuidado especial para que o negócio se realize nas melhores condições possíveis.

Após passar pela barreira de Itapetininga, situada próxima à fronteira com a província do Paraná, as tropas não eram necessariamente conduzidas à feira, de imediato. Poderiam ser colocadas em estações de invernagem da região, onde seriam adequadamente tratadas e ficariam à espera de condições de mercado mais favoráveis. A comparação entre as séries de Itapetininga e Sorocaba parece indicar ter sido esta prática bastante comum durante o período em estudo. Neste sentido, as flutuações menos intensas registradas no fluxo por Sorocaba estariam relacionadas a um controle da oferta nos mercados da cidade por parte dos negociantes de mulas, através da retenção de suas tropas nos pastos de invernagem da região meridional da província.Tal constatação, se confirmada, ofereceria evidências bastante claras acerca da complexidade do sistema de comercialização dos muares.

Ao tentar explicar a crise verificada durante a década de 1860, KLEIN (1989, p. 356) argumenta estar ela relacionada a distúrbios de oferta ("dificuldades climáticas e de produção") - embora não ofereça evidências em suporte a esta idéia. Entretanto, a dinâmica de passagem de tropas por Itapetininga parece apontar para uma outra possibilidade totalmente diversa. Considerando-se que o mercado consumidor - a demanda - está mais bem representado pelas movimentações de Sorocaba do que pelas de Itapetininga, dado que Sorocaba é o locus por excelência da comercialização dos animais, e aceitando-se ainda a evidência de que o fluxo de Sorocaba reflete as bruscas movimentações de Itapetininga, porém de forma diluída no tempo, seria de se esperar que uma crise de oferta, surgindo primeiramente em Itapetininga, seria gradualmente absorvida nas movimentações de Sorocaba.

Como pode ser visto no gráfico 3, não foi isso que ocorreu com a crise iniciada em 1861/62. Quando ocorre o brusco declínio na movimentação em Itapetininga, durante o ano financeiro 1862/63, o volume de muares conduzidos por Sorocaba já se encontra em franco declínio, suavizando sua queda já no ano seguinte, quando o fluxo em Itapetininga volta a tomar trajetória ascendente, até alcançar um patamar compatível com a movimentação de Sorocaba no ano financeiro 1864/65. Da mesma forma, a recuperação do mercado nos dois últimos anos do decênio é liderada por Sorocaba - provavelmente através da negociação do que resta- 
va dos estoques de animais acumulados no período 1858/59 - 1861/62 com o fluxo de Itapetininga ajustando-se gradualmente.

Estas evidências parecem indicar, ao contrário do proposto por Klein, que a crise da década de 1860 foi desencadeada primordialmente por fatores de demanda. Ainda como suporte adicional a esta idéia, vemos o presidente da Província do Paraná, em um relatório referente ao ano financeiro 1862/63, recorrer à "crise havida o anno passado na feira de Sorocaba, que desanimou os negociantes de animaes $[\ldots]^{118}$, ao explicar a queda registrada na receita provincial. Tal crise ocorrera, portanto, na feira de 1862 - ano em que o fluxo em Sorocaba principia seu declínio, porém em Itapetininga ainda se mantém em níveis elevados.

Infelizmente, não encontramos evidências mais claras acerca da natureza dos distúrbios de demanda possivelmente associados com esta crise de princípios da década de 1860. Uma possível explicação talvez resida nos progressos verificados por esta época na instalação da rede ferroviária. Dado que o transporte de cargas com bestas era realizado, em sua maior parte, por tropeiros especializados, que detinham seus próprios estoques de animais, a expectativa em relação à chegada das ferrovias pode ter atuado no sentido de inibir novas compras de animais, mantendo-se apenas os estoques já adquiridos. Uma decisão como esta refletiria diretamente sobre o fluxo de comércio de animais - justamente o fenômeno observado nos dados de Itapetininga e Sorocaba. Por outro lado, a recuperação observada em meados da década está provavelmente relacionada ao choque expansionista de demanda agregada, associado à eclosão da Guerra do Paraguai.

\section{IV - Distribuição das tropas e concentração}

Quando passamos a analisar o fluxo de animais pela barreira de Itapetininga sob a ótica do número de tropas conduzidas - e não em relação ao número total de animais, como vínhamos fazendo até agora uma característica peculiar a esta perspectiva salta aos olhos, embora a tendência de evolução ao longo do tempo permaneça a mesma, em traços gerais. No gráfico 4 exibimos três séries relativas ao número de tropas

Relatório do Presidente da Província do Paraná, 15 de fevereiro de 1863, p. 29.

621 Carlos Eduardo Suprinyak 
conduzidas pela barreira durante o período. Em uma delas, isolamos apenas as tropas em que se verificou a existência de muares (independente da presença ou não de animais de outros rebanhos); em uma segunda série, fizemos o mesmo para as tropas contendo cavalos; por fim, a última série mostra a evolução do número total de tropas conduzidas pela barreira.

Gráfico 4. Número de tropas conduzidas pela barreira de Itapetininga, segundo rebanho de animais, $1854 / 55-1868 / 69$

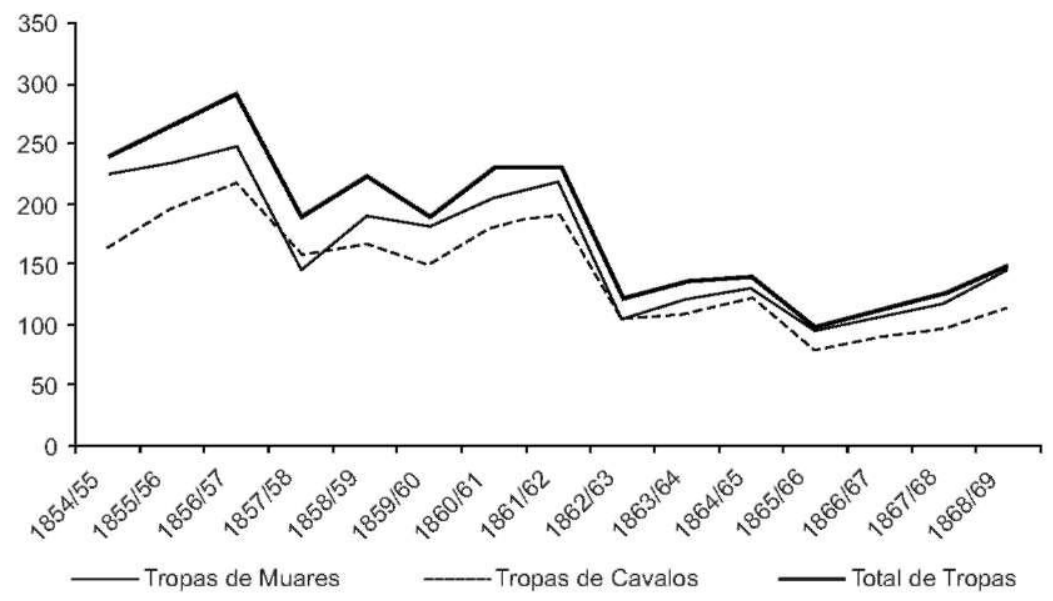

Conforme podemos observar, o padrão de comportamento das três séries é similar. Não apenas suas flutuações ao longo do tempo assumem as mesmas formas, como também o próprio número absoluto de tropas conduzidas, em cada uma delas, é bastante semelhante. Esta constatação parece apontar de forma inequívoca para a existência de uma marcada interpenetração dos dois rebanhos na composição das tropas conduzidas por Itapetininga. Com efeito, tal suspeita é confirmada, quando separamos as tropas conduzidas no período em três categorias: as compostas exclusivamente por muares, as compostas exclusivamente por cavalares (cavalos e éguas) e ainda um terceiro tipo, contendo animais de ambos os rebanhos, doravante denominadas tropas mistas. A distribuição das tropas de acordo com esta classificação é apresentada na tabela 2 .

Pode-se verificar que as tropas mistas compõem mais de $70 \%$ do total das tropas passadas pela barreira de $1854 / 55$ a $1868 / 69$, responden- 
do por mais de $76 \%$ do total dos animais conduzidos no período. Assim sendo, a despeito da sazonalidade diversa apresentada pelo fluxo de rebanhos cavalares e muares, parece haver um grau razoável de integração entre os dois mercados - no caso específico, evidenciado pela participação de um grande número de negociantes em ambos. Esta constatação é importante para a análise da concentração do negócio dos animais através da distribuição do tamanho das tropas, dado que, se há uma integração forte entre os dois rebanhos na composição das tropas conduzidas, seria pouco recomendável isolar apenas um deles para análise, sob pena de distorcer gravemente os resultados.

Uma tropa com menos de 50 muares e mais de 100 cavalos seria considerada pequena, quando observada estritamente sob o ponto de vista do mercado de muares, porém torna-se uma tropa média, quando vista em seu conjunto. Como estamos interessados em determinar a concentração de um negócio - um sistema econômico complexo - tal separação provavelmente traria resultados menos confiáveis, dado que um grande negociante pode estar envolvido em transações com predominância de rebanho muar ou cavalar, alternativamente. Para confirmar tal asserção, consideremos ainda o seguinte: as tropas compostas por mais de 100 muares e menos de 20 cavalos - i.e., as tropas mistas, para as quais se pode afirmar, com alguma certeza, que os cavalares desempenham um papel meramente incidental - representam apenas $52,1 \%$ do total de tropas mistas conduzidas, apesar de responderem por mais de $75 \%$ do total de animais e mais de $84 \%$ do total dos muares. Desta forma, ainda restam 47,9\% do total de tropas mistas, em cuja composição se verifica um razoável equilíbrio entre os dois rebanhos. $\mathrm{Na}$ análise da concentração do negócio (segundo o tamanho das tropas) que pretendemos desenvolver, parece-nos essencial considerar juntamente ambos os rebanhos.

Dentro desta perspectiva, vejamos como se distribuem as tropas de acordo com seu tamanho, dividindo-as em quatro faixas: menos de 100 animais, entre 100 e 250 animais, entre 250 e 500 animais e mais de 500 animais. A tabela 3, onde tal distribuição é apresentada, fornece indícios claros acerca da presença de concentração no negócio de animais de carga. A participação de cada faixa no total das tropas e no total dos animais conduzidos evolui de maneira inversamente proporcional. A última faixa, onde são computadas as tropas grandes (mínimo 
de 500 animais), enquanto representa apenas $16,8 \%$ do total das tropas, é responsável por mais de $42 \%$ do total de animais, enquanto a primeira faixa (menos de 100 animais), contendo quase $27 \%$ do total das tropas conduzidas, responde por pouco mais de $6 \%$ do total de animais.

A presença constante de grandes negociantes, responsáveis isoladamente pelo comércio de enormes quantidades de animais, reflete-se em casos como o do Comandante Fidelis Nepomuceno Prates. Consta dos registros de Itapetininga que, a 24 de abril de 1861, Higino Jozé Rolim de Oliveira - tropeiro, cujo nome aparece com freqüência nos registros - conduziu uma tropa de propriedade do comandante, composta por nada menos que 1555 bestas, além de um cavalo. O valor dos direitos devidos por esta tropa, tão somente, aproxima-se da vultosa quantia de quatro contos de réis. Mais tarde, em 1867, vemos o referido comandante fazer passar mais uma tropa, a 15 de dezembro, sempre pelas mãos de terceiros, desta vez contendo 1008 bestas e dois cavalos, para, apenas três meses depois, a 20 de março de 1868, conduzir mais 1500 bestas e três cavalos. A 4 de janeiro do ano seguinte, o comandante marcaria presença mais uma vez, constando nos registros uma tropa de suas ordens composta por 1279 bestas e sete cavalos.

De menor expressão, porém igualmente ilustrativo, é o caso de Pedro Prestes da Silva, negociante domiciliado em Guarapuava que, ao contrário do Comandante Prates, conduzia ele próprio suas tropas. Consta dos registros que, a 13 de maio de 1866, conduziu uma tropa contendo 1068 mulas, além de dois cavalos e uma égua. No ano seguinte, Pedro fez mais uma aparição de vulto, conduzindo, a 15 de junho, uma tropa composta por 1124 bestas e 12 cavalos.

Quando se observa o comportamento da distribuição das tropas por faixas de tamanho ao longo do tempo, podem-se entrever alguns padrões interessantes. Os dados apresentados na tabela 4 evidenciam que a crise dos anos 60, embora tenha atingido os negociantes de todas as faixas, afetou-os de maneiras diversas. Isto é particularmente evidente nos números relativos ao total de animais, verifica-se que, embora as duas faixas superiores tenham sido as mais afetadas pela crise, também foram elas as que responderam mais vigorosamente à recuperação no final da década, ao passo que as duas faixas inferiores, perdendo espaço de maneira mais gradual ao longo da década, não demonstram sinais claros de retomada das atividades no final do período. 
Chama a atenção o fato de que a segunda faixa (composta por tropas médias de menor porte) demonstra uma tendência declinante ao longo de todo o período, reduzindo sua participação mesmo durante a fase de apogeu, ao final da década de 1850 . Isto é verdade tanto com relação ao número de tropas quanto ao volume de animais conduzidos. Tal tendência fica ainda mais clara ao se observar os gráficos 5 e 6, que exibem a evolução da participação relativa de cada faixa no total das tropas e dos animais conduzidos por Itapetininga. respectivamente.

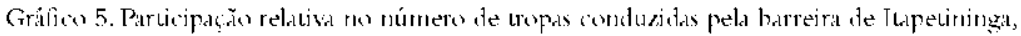
scgundo faixis de tamanho, $1854 / 55-1868 ; 60$

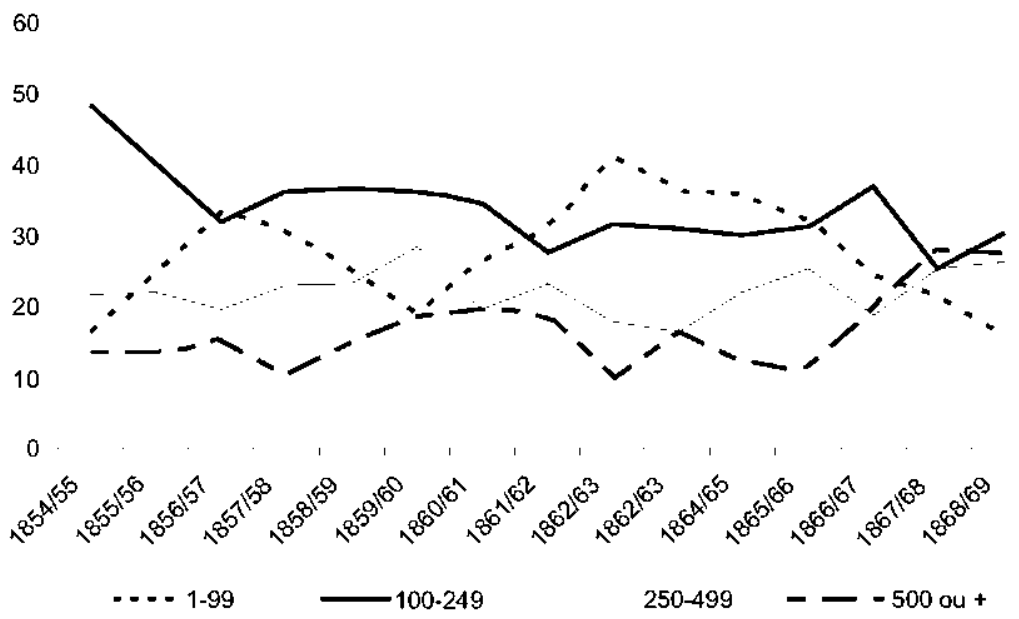

Como se pode inferir a partir dos gráficos, houve um marcado declínio na participação relativa da segunda faixa, cuja parcela parece ter sido absorvida pela última faixa (tropas grandes), em sua maior parte. No caso das tropas conduzidas, verifica-se um certo equilíbrio entre as diversas faixas no final do período, com a primeira e a terceira faixas logrando manter suas participações iniciais, apesar das flutuações. A primeira faixa, com efeito, passa por uma fase de franca ascensão no início da década de 1860 , entrando em declínio constante a partir do início da crise até o final do período. A segunda faixa, conforme mencionado, perde em posição relativa, enquanto a última melhora sua posição, especialmente nos últimos três anos. 
Gráfico 6. Participação relativa no número de animais conduzidos pela barreira de Itapetininga, segundo faixas de tamanho, 1854/55-1868/69

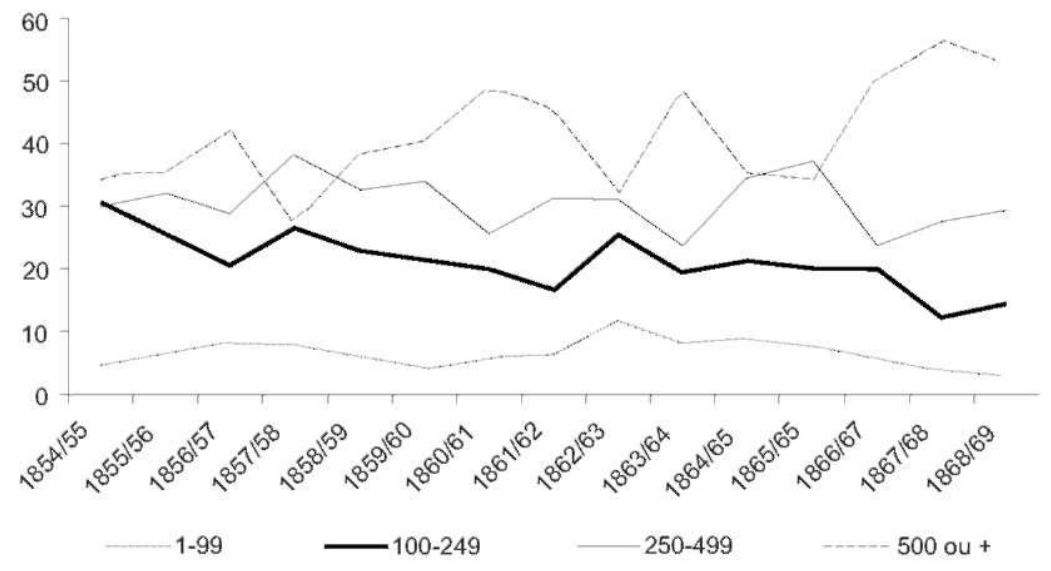

A evolução das participações relativas no total de animais conduzidos apresenta um quadro ainda mais evidente. A terceira faixa, após algumas oscilações, mantém sua posição relativa. Tal não ocorre com a segunda, que apresenta uma tendência declinante quase constante. A primeira faixa, contendo as tropas pequenas, após aumentar sensivelmente sua participação relativa no início da década de 60 , perde espaço constantemente até o final do período. A parcela destas duas últimas parece ter sido absorvida, em grande medida, pelos grandes negociantes de tropas, cuja participação relativa, após muita oscilação, aumenta sensivelmente nos últimos três anos do período estudado.

Entretanto, quando abandonamos a classificação das tropas segundo faixas de tamanho, surgem algumas evidências diversas quanto à estruturação do mercado de animais. Na tabela 5, apresentamos a evolução anual dos índices de GINI, calculados sobre a distribuição das tropas, como estimativa do grau de concentração do negócio. Como se pode observar, o grau de concentração acompanha, aproximadamente, as movimentações no volume de animais conduzidos, até o ano financeiro 1861/62 - justamente quando surgem os primeiros sintomas de crise em Sorocaba. Esta evidência pode indicar que, até a deflagração da crise na década de 60 , as oscilações no mercado de animais, tanto para cima quanto para baixo, eram absorvidas em grande medida pelos comerciantes de grande porte - asserção corroborada pela evolução apresentada nos gráficos 5 e 6 . 
Tal padrão é rompido em 1861/62, quando concentração e volume conduzido andam em direções opostas, embora as mudanças relativas sejam pouco significativas. Entre 1862/63, tal tendência se agrava, caindo o volume conduzido a menos da metade do verificado no ano anterior, enquanto o índice de concentração aumenta significativamente. Também no ano seguinte, acompanhando a discreta recuperação no fluxo de animais, a concentração cresce ainda mais, atingindo seu ponto máximo no período. A partir de 1864/65, entretanto, o índice de concentração inicia um declínio que se estenderá até o fim do período, enquanto o volume conduzido, à exceção do período entre 1865/66, crescerá continuamente.

Tal constatação é bastante intrigante no que se refere aos três últimos anos da série - o período de recuperação da crise, para o qual os gráficos 5 e 6 demonstram crescente predomínio dos grandes negociantes no total do comércio. Aparentemente, a explicação para esta evidência, de certo modo contraditória, repousa em menor concentração na distribuição das tropas dentro de cada faixa. $\mathrm{O}$ número médio de animais conduzidos por tropa dentro da última faixa - a que contém as grandes tropas - após atingir 771 animais em 1855/56, cai para pouco mais de 738 e de 717 nos dois anos seguintes, registrando no último ano da série apenas 666 animais por tropa. Em outras palavras, embora a participação dos grandes negociantes no total de animais conduzidos tenha aumentado no final do período, sua participação no total das tropas aumentou mais do que proporcionalmente, levando a um menor nível de concentração dentro da própria classe. A mesma explicação, em sentido oposto, vale para a quebra de 1862/63 - o número de tropas caiu mais do que proporcionalmente ao número de animais, levando a uma maior concentração, embora neste ano isto tenha ocorrido em todas as faixas, à exceção da terceira. Assim sendo, parece possível aventar a hipótese de que a crise, ao eliminar os negociantes de menor fôlego, teria fortalecido a posição dos de maior porte, conduzindo a uma maior concorrência nas camadas superiores do negócio.

A análise de concentração aqui desenvolvida - baseada exclusivamente na distribuição do tamanho das tropas, sem considerar informações sobre a propriedade destas - oferece apenas uma representação aproximada das nuances estruturais do negócio de animais no período. Ao deixar de lado a possibilidade de que um dado negociante possa ter conduzido mais de uma tropa em um mesmo ano financeiro, introdu- 
zimos claramente um viés de baixa em nossas estimativas. Entretanto, as altas exigências de uma transação com tropas, tanto em termos de tempo quanto de recursos financeiros, tendem a reduzir significativamente a magnitude deste viés. De fato, casos como o do Comandante Prates, que em um mesmo ano financeiro pôde conduzir duas tropas com mais de mil animais cada, parecem ter sido a exceção, e não a regra. Desta forma, acreditamos que as estimativas aqui registradas representam um quadro no mínimo bastante acurado acerca da evolução da estrutura do mercado de animais no terceiro quartel do século XIX.

\section{Referências bibliográficas}

ALMEIDA, A. de, "Achegas à biografia do Barão de Antonina", Revista do Arquivo Municipal, CXVI, São Paulo: Departamento Municipal de Cultura, 1947.

CALÓgeras, J. P., Transportes arcaicos no Brasil, Boletim Geográfico, Rio de Janeiro: IBGE, a. II, n. 23, fev. 1945, pp. 1670-1677.

COSTA, H. M., "As barreiras de São Paulo: estudo histórico das barreiras paulistas no século XIX", Dissertação de Mestrado, Departamento de História da FFLCH/USP, 1984. ELliS JR., A., "O ciclo do muar", Revista de História, a. I,jan-mar 1950, pp. 73-81.

A economia paulista no século XVIII: o ciclo do muar, o ciclo do açúcar, São Paulo: Academia Paulista de Letras, 1979.

FURTADO, C., Formação econômica do Brasil, São Paulo: Companhia Editora Nacional, 2001.

HAMEISTER, M. D, "O Continente do Rio Grande de São Pedro: os homens, suas redes de relações e suas mercadorias semoventes (c.1727-1763)", Dissertação de Mestrado, UFRJ, 2002.

KLEIN, H. S., "A oferta de muares no Brasil central: o mercado de Sorocaba, 18251880", Estudos Econômicos, v. 19, n. 2, mai-ago 1989.

LAVALlE, A. M., "Análise quantitativa das tropas passadas no registro do Rio Negro (1830-1854)", Tese de Livre Docência, UFPR, 1974.

MOREIRA, J. E., Caminhos âas comarcas de Curitiba e Paranaguá, Curitiba: Imprensa Oficial, 3 vs., 1975.

MÜLleR, D. R, Ensaio d'um quadro estatístico da província de São Paulo, São Paulo: Governo do Estado, 1978.

PETRONE, M. T. S., O Barão de Iguape, um empresário da época da Independência, São Paulo: Companhia Editora Nacional, 1976.

PRADO JR., O, História econômica do Brasil, São Paulo: Brasiliense, 2000. Formação do Brasil contemporâneo, São Paulo: Brasiliense, 2001.

Relatório dos Presidentes das Províncias de São Paulo e Paraná, in http://brazil.crl.edu/ content/provopen.htm (cf. consultado em 03/2005).

WestPhalen, C. M., O Barão dos Campos Gerais e o comércio de tropas., Curitiba: CD Editora, 1995. 
ANEXOS

Tabela 1.Volume de animais conduzidos anualmente pela barreira de Itapetininga, $1854 / 55-1868 / 69$

\begin{tabular}{ccccc}
\hline Ano Financeiro & Muares & Cavalos & Éguas & Total \\
\hline $1854 / 55$ & 51.102 & 8.213 & 251 & 59.566 \\
$1855 / 56$ & 56.645 & 7.808 & 122 & 64.575 \\
$1856 / 57$ & 61.097 & 9.753 & 147 & 70.997 \\
$1857 / 58$ & 32.549 & 9.835 & 278 & 42.662 \\
$1858 / 59$ & 50.184 & 7.865 & 516 & 58.565 \\
$1859 / 60$ & 48.720 & 6.006 & 245 & 54.971 \\
$1860 / 61$ & 57.043 & 7.021 & 192 & 64.256 \\
$1861 / 62$ & 54.001 & 6.980 & 343 & 61.324 \\
$1862 / 63$ & 19.986 & 4.939 & 330 & 25.255 \\
$1863 / 64$ & 28.285 & 4.943 & 128 & 33.356 \\
$1864 / 65$ & 28.380 & 4.845 & 270 & 33.495 \\
$1865 / 66$ & 22.254 & 2.201 & 54 & 24.509 \\
$1866 / 67$ & 29.790 & 3.162 & 64 & 33.016 \\
$1867 / 68$ & 40.464 & 3.807 & 98 & 44.369 \\
$1868 / 69$ & 50.402 & 2.446 & 75 & 52.923 \\
\hline
\end{tabular}

Fonte: AESP, Livros de Barreiras — Itapetininga.

Tabela 2. Número total de tropas conduzidas pela barreira de Itapetininga, segundo composição, $1854 / 55$ - $1868 / 69$

\begin{tabular}{lcrrrc}
\hline Tipo de Tropa & N- Tropas & \multicolumn{1}{c}{$\%$} & N-Animais & $\%$ & Média p/ tropa \\
\hline Apenas Muares & 565 & 20,06 & 146.060 & 19,83 & 258,51 \\
Muares e Cavalares & 1.977 & 70,21 & 561.927 & 76,30 & 284,23 \\
Apenas Cavalares & 274 & 9,73 & 28.514 & 3,87 & 104,07 \\
Total & 2.816 & 100,00 & 736.501 & 100,00 & \\
\hline
\end{tabular}

Fonte: AESP, Livros de Barreiras — Itapetininga. 
Tabela 3. Distribuição das tropas conduzidas por Itapetininga segundo faixas de tamanho, $1854 / 55$ - $1868 / 69$

\begin{tabular}{cccccc}
\hline Faixa & N- Tropas & $\%$ & N- Animais & $\%$ & Média $\mathrm{p} /$ tropa \\
\hline $1-99$ & 766 & 26,92 & 46.059 & 6,13 & 60,13 \\
$100-249$ & 978 & 34,38 & 157.439 & 20,97 & 160,98 \\
$250-499$ & 623 & 21,90 & 227.032 & 30,24 & 364,42 \\
500 ou + & 478 & 16,80 & 320.240 & 42,65 & 669,96 \\
Total & 2.845 & 100,00 & 750.770 & 100,00 & \\
\hline
\end{tabular}

Fonte: AESP, Livros de Barreiras — Itapetininga.

Tabela 4. Número anual de tropas e animais conduzidos por Itapetininga, segundo faixas de tamanho, $1854 / 55$ - $1868 / 69$

\begin{tabular}{|c|c|c|c|c|c|c|c|c|c|c|}
\hline \multirow[t]{2}{*}{ Ano } & \multicolumn{5}{|c|}{ Tropas } & \multicolumn{5}{|c|}{ Animais } \\
\hline & $1-99$ & $100-249$ & $250-499$ & $500+$ & Total & $1-99$ & $100-249$ & $250-499$ & $500+$ & Total \\
\hline $1854 / 55$ & 39 & 116 & 52 & 33 & 240 & 2.808 & 18.199 & 17.940 & 20.619 & 59.566 \\
\hline $1855 / 56$ & 64 & 108 & 58 & 35 & 265 & 3.950 & 16.832 & 20.740 & 23.053 & 64.575 \\
\hline $1856 / 57$ & 98 & 93 & 57 & 44 & 292 & 5.809 & 14.556 & 20.577 & 30.055 & 70.997 \\
\hline $1857 / 58$ & 58 & 69 & 44 & 19 & 190 & 3.372 & 11.274 & 16.393 & 11.623 & 42.662 \\
\hline $1858 / 59$ & 56 & 81 & 52 & 33 & 222 & 3.544 & 13.413 & 19.102 & 22.506 & 58.565 \\
\hline $1859 / 60$ & 35 & 69 & 54 & 33 & 191 & 2.245 & 11.927 & 18.664 & 22.135 & 54.971 \\
\hline $1860 / 61$ & 61 & 80 & 45 & 45 & 231 & 3.713 & 12.657 & 16.531 & 31.355 & 64.256 \\
\hline $1861 / 62$ & 71 & 64 & 53 & 43 & 231 & 3.833 & 10.203 & 19.244 & 28.044 & 61.324 \\
\hline $1862 / 63$ & 51 & 39 & 22 & 12 & 124 & 2.906 & 6.460 & 7.865 & 8.024 & 25.255 \\
\hline $1863 / 64$ & 49 & 42 & 22 & 22 & 135 & 2.735 & 6.473 & 7.898 & 16.250 & 33.356 \\
\hline $1864 / 65$ & 50 & 42 & 31 & 17 & 140 & 2.863 & 7.167 & 11.621 & 11.844 & 33.495 \\
\hline $1865 / 66$ & 32 & 31 & 25 & 11 & 99 & 1.884 & 4.972 & 9.172 & 8.481 & 24.509 \\
\hline $1866 / 67$ & 27 & 41 & 21 & 22 & 111 & 1.837 & 6.497 & 7.720 & 16.245 & 32.299 \\
\hline $1867 / 68$ & 27 & 32 & 32 & 35 & 126 & 1.655 & 5.369 & 12.252 & 25.093 & 44.369 \\
\hline $1868 / 69$ & 24 & 45 & 39 & 41 & 149 & 1.529 & 7.611 & 15.645 & 28.138 & 52.923 \\
\hline
\end{tabular}

Fonte: AESP, Livros de Barreiras — Itapetininga. 
Tabela 5. índice de gini para a distribuição das tropas conduzidas por Itapetininga, segundo seu tamanho, 1854/55 — 1868/69

\begin{tabular}{|c|c|c|}
\hline Ano Financeiro & Índice de GINI & Volume conduzido \\
\hline $1854 / 55$ & 0,390 & 59.566 \\
\hline $1855 / 56$ & 0,435 & 64.575 \\
\hline $1856 / 57$ & 0,480 & 70.997 \\
\hline $1857 / 58$ & 0,433 & 42.662 \\
\hline $1858 / 59$ & 0,436 & 58.565 \\
\hline $1859 / 60$ & 0,397 & 54.971 \\
\hline $1860 / 61$ & 0,465 & 64.256 \\
\hline $1861 / 62$ & 0,467 & 61.324 \\
\hline $1862 / 63$ & 0,481 & 25.255 \\
\hline $1863 / 64$ & 0,517 & 33.356 \\
\hline $1864 / 65$ & 0,474 & 33.495 \\
\hline $1865 / 66$ & 0,473 & 24.509 \\
\hline $1866 / 67$ & 0,465 & 32.299 \\
\hline $1867 / 68$ & 0,431 & 44.369 \\
\hline $1868 / 69$ & 0,399 & 52.923 \\
\hline
\end{tabular}

Fonte: AESP, Livros de Barreiras — Itapetininga. 